\title{
Facilitate ESL Class Participation: Establishing and Maintaining an Online Community of Learners
}

\author{
Dian Jiang \\ University of Southern California, United States \\ Hong Kong University of Science and Technology, HKSAR
}

\begin{abstract}
The COVID-19 pandemic has presented unprecedented challenges to instructors of higher education. As a result, the level of instruction and student participation has also been affected. Amid navigating technical literacies, maintaining and elevating students' online class participation is instructors' most concern. This study explores one graduate course whose majority of students are ESLs at a U.S. university utilizing a synchronous meeting tool to deliver classes. The study aims to figure out the impact learning online exerted on Graduate-level ESL and the essential factors related to active students' participation. Data of this study was collected through observations and analyzed through the theory of Community of Inquiry (CoI). Analytical data highlighted a relative increase in-class participation in written and oral forms compared to the first set of on-ground classes. The study indicated that the crux of an engaging online course is creating a shared social identity or group commitment, which leads to an online community instead of a class of learners. A set of contributors to cohesive group identity are identified, all of which naturally fall into the three presences of an online CoI. Implications and practical teaching tips for establishing an online community and elevating ESL students' class participation are presented in this article.
\end{abstract}

Keywords: online community, Community of Inquiry (CoI), ESL, participation, E-learning

\section{Introduction}

The pandemic presented unprecedented challenges for education practitioners and students. As a result, online teaching has become the new norm in the post-pandemic. This study was based on class observations of one course of the MAT-TESOL program at a University in the United States. Since the second half of the semester, the school was forced to adopt online teaching due to Covid-19 (from week 9 to week 15). The constitution of the class is international ESLs and English-native speakers, with ESL accounting for 92\%. The author noticed an increase in ESLs' class participation from week 10. To test and verify this observation, the author took observation logs and analyzed the information through the lens of Community of Inquiry (CoI) theory. Analytical data indicates that establishing and maintaining a collaborative and supportive online community of learners is essential for promoting ESLs' class participation. Implications and a couple of practical teaching advice to this aim are given. 


\section{Related Literature}

\subsection{Community of Inquiry}

A community of inquiry focusing on establishing a community of learners that engaged in inquiry activities (e.g., creating meaning and confirming understanding) actively and collaboratively (Garrison, 2009). The author acclaimed, construction of knowledge in a collaborative environment such as a community of inquiry beyond simply sharing or disseminating information, requiring purposeful communication, critical reflections, and class engagement(Garrison, 2009). Garrison et al. (1999) proposed three elements of a community of inquiry for educational purposes: social, cognitive, and teaching presences. The core concept of cognitive presence lies in constructing and validating meanings through sustained communication (Cho \& Tobias, 2016). Social presence emphasized "the ability of participants in the Community of Inquiry to project their characteristics into the community, thereby presenting themselves to the other participants as 'real people" (Garrison et al., 1999). As the most significant factor of establishing a CoI, social presence facilitates the construction of knowledge, promotes the critical thinking process, and builds up a social identity within the learners by eliminating isolation and loneliness (Cho \& Tobias, 2016; Garrison et al., 1999). Teaching presence mainly balances the other two presences to facilitate the creation of a community of inquiry (Garrison et al., 1999). The concepts of Community of Inquiry are being used extensively in online learning as guidance for course design and delivery(Garrison, 2009).

\subsection{Online Learning Community (OLC)}

The definition of a learning community is comprised of three elements: a common place for learning to take place, group works through which people learn, and the targeted new knowledge and skills. The three elements and interactions in an online setting refer to the Online Learning Community (OLC). Researches have shown that social presence is essential for establishing an ideal online learning community as it ensures the online interactions necessary for sustaining the community activities.

\subsection{Online Participation}

The present study adopted the definition of participation proposed by Hrastinski (2009). Hrastinski defines online learner participation as "a process of learning by taking part and maintaining relations with others. It is a complex process comprising doing, communicating, thinking, feeling and belonging, which occurs both online and offline" (p. 1761). The present study adopted the definition of participation proposed by Hrastinski as

\section{Methods}

The research process was guided by two main questions: (1) Is there an increase in ESL participation in online classes? (2) If any, what's the root of this elevated participation level? 
Class diaries for 12 consecutive sessions generate a set of observational data. Entries in the observational logs include class dates, themes, class rapport, student participation level, exceptional cases, and the researchers' subjective comments on each lesson. Also, the researcher referred to class recordings to supplement details.

\section{Results and Discussion}

Analytical data indicated increased participation among ESL students and identified a set of components conducive to elevated involvement. Those factors naturally fell into the three presences of an online Community of Inquiry.

\subsection{Cognitive Presence \& Teaching presence}

Two ways to realize cognitive presence are 1) implementation of group works and 2) the composition of course content. The breakout group function of the synchronous meeting tool makes it possible to implement various collaborative activities in an online setting, such as small group discussions. The construction and validation of meanings are mainly realized in this way. Other factors affecting students' cognitive development and engagement level are features of course content: difficulty level, relevancy of the topic with students' lives, and criticality involved in the course design.

The teaching presence is composed of two elements: 1) the instructor's facilitation of group works and 2) the instructor's multitasking ability. Well-organized collaborative activities are paramount for students' critical thinking development and understanding of the course content. Moreover, the instructor's multitasking ability is another vital factor for the feelings and experience of the students, exerting impact on students' wiliness to participate.

\subsection{Social Presence}

Three factors are identified as essential for maintaining a high social presence: synchronous communications, collaborative group activities, and a supportive class rapport. Regarding group identity and creating a community of learners, a built-in Chatbox where communications take place co-constructs group cohesion with the implementation of group works. Implementing group activities is vital to establish a sense of belonging and group commitment and to elicit students to share personal meaning. Furthermore, the positive class rapport built in the first eight-week on-ground classes contributed to a higher comfort level, effectively lowering ESL students' affective filters to participate in class orally.

\subsection{Findings}

There came one main finding from the data analysis:

The design, facilitation, level of criticality (higher-order thinking), and opportunities for communal development are essential to supporting and sustaining a community of learners. 
The responsibility of creating a community of learners does not fall upon the teacher, but it does start with the teacher- modeling community-and collaborative-based practices. A couple of practical teaching tips for online instructors are listed below.

\subsection{Teaching Tips}

1. Implementing group works that enable all students to participate actively and equally in class. By doing so, the instructor creates opportunities for all students to be engaged in the class, contributing to group commitment.

2. Various group formation can ensure that each student will work with all other peers after the first couple of weeks. Through contact with each other, the class will gradually establish community identity.

3. Warm up the class with a casual talk or brainstorm the topic to start the conversation and create a supportive class vibe.

4. Instructors can participate in the chatbox interactions with students by posting emoticons, making comments on students' posts, and sharing personal stories, shortening the psychological distance between the students and teachers.

\section{Conclusion}

This study derived from the author's observation of one online graduate course at a university in the U.S. The study results indicated that ESL class participation was increased when the class moved online. The finding reveals the fact that to facilitate ESL class participation, establishing and maintaining a supportive and collaborative online community of learners is crucial. The goal can be achieved through addressing the components of the three presences of CoI, with a particular focus on those of social presence. In sum, the crux of efficient and engaging online teaching lies in the construction of social identity and commitment.

\section{References}

Cho, M.-H., \& Tobias, S. (2016). Should instructors require discussion in online courses? Effects of online discussion on community of inquiry, learner time, satisfaction, and achievement. International Review of Research in Open and Distributed Learning, 17(2), 123-140.

Garrison, D. R. (2009). Communities of inquiry in online learning. In Encyclopedia of distance learning, Second edition (pp. 352-355). IGI Global.

Garrison, D. R., Anderson, T., \& Archer, W. (1999). Critical inquiry in a text-based environment: Computer conferencing in higher education. The internet and higher education, 2(2-3), 87-105.

Hrastinski, S. (2009). A theory of online learning as online participation. Computers \& Education, 52(1), 78-82. 
Garrison, D. R. (2009). Communities of Inquiry in Online Learning. In Encyclopedia of Distance Learning, Second Edition (pp. 352-355). https://doi.org/10.4018/978-160566-198-8.ch052 